\title{
Knowledge, Attitude, Practice and Associated Factors of Kangaroo Mother Care for Neonatal Survival Among Care Takers of Preterm and Low Birth Weight Infants in Health Care Settings, Hawassa, Southern Ethiopia, 2018
}

\author{
Getinet Kassahun $^{1^{*}} \quad$ Aberash Efa $^{1} \quad$ Haymanot Samuel $^{2}$ \\ 1.Department of Midwifery, College of medicine and health science, Hawassa University, PO box 1560, \\ Hawassa, Southern Ethiopia \\ 2.Hawassa University comprehensive specialized hospital, PO box 1560, Hawassa, Southern Ethiopia
}

\begin{abstract}
Background: In Ethiopia, preterm and low-birth weight is the leading cause of neonatal morbidity and Mortality. Many of these deaths can be prevented using Kangaroo Mother Care (KMC) which has been proven and costeffective intervention especially in low- and middle-income countries. However, there is presently a lack of $\mathrm{KMC}$ data in the region on the barriers causing a low record for $\mathrm{KMC}$, is it attitude or knowledge. Hence, the purpose of this study was to explore the knowledge, attitude, practices and associated factors of KMC among caretakers of preterm and LBW infants. Methods: A facility-based cross-sectional study was done in KMC centers on 93 care takers in Hawassa health care settings from March 2018 to April 2018. Study participants were selected using a convenient random sampling technique. Data were collected through questionnaire interviews and extract information during review of records and observation. These data were cleaned, coded and entered using EpiData Version 3.1 statistical software then transferred to SPSS software package version 22 for analyses and explained with texts, figures and tables. Pearson chi-square was computed to test the association between independent and outcome variables. P-value of chi-square $\left(\mathrm{X}^{2}\right)<0.05$ with $95 \% \mathrm{CI}$ was confirmed as statistically significant. Results: Fifty nine (68.6\%) study participants were knowledgeable on Kangaroo mother care and $61.6 \%$ had the good practice of KMC. Three variables (having delivery in KMC health care setting $(\mathrm{p}=0.018)$, being skilled birth attendant $(\mathrm{p}=0.0001)$ and getting $\mathrm{KMC}$ counseling $(\mathrm{p}=0.001))$ had statically significant association with knowledge of caregivers regarding to $\mathrm{KMC}$, whereas two variables (being knowledgeable on $\mathrm{KMC}(\mathrm{p}=0.001)$ and being skilled birth attendant $(\mathrm{p}=0.006))$ had statically significant association with caregivers' practice of Kangaroo mother care. Conclusion: Our study shows that overall knowledge and practice of care takers of premature and low birth weight infants regarding KMC was low. Some factors of care takers affect the knowledge and practice of KMC for caring in premature and LBW infants. Recommendation: KMC counseling and education should be conducted during ANC follow up and delivery should be assisted by skilled birth attendant in KMC health care settings to improve their knowledge. Besides, knowledge of KMC should be generated to increase the practice of KMC.
\end{abstract}

Keywords: KMC, knowledge, attitude, practice care takers, associated factors, Ethiopia

DOI: $10.7176 / \mathrm{JHMN} / 58-01$

\subsection{Background}

LBW and preterm birth account $60-80 \%$ of neonatal deaths worldwide. The three leading causes of neonatal mortality and morbidity are infections (35\%), preterm birth and LBW (28\%) and asphyxia (23\%) [1]. globally, around 25 million and 15 million newborns were low birth weight and preterm newborns respectively. Of this, developing countries account $96 \%$ of preterm and LBW infants [2, 3]. Small infants related problems that can be fatal and disabling such as unable to control their body temperature and infection [4]. In developing countries, the risk of death in small infants is six-times greater than in developed countries [5].

In 2016, of all 1,897,829 institutional live births, 8,570 preterm live births ( $<37$ weeks), 49,201 low birth weight $(<2,500$ grams), and 4,225 very low birth weight $(<1,500$ grams). In Ethiopia, these statistics is lower than the actual figures as under-reporting and lack of neonatal death registries at home. There are higher figure of premature and LBW infants in higher health facilities than primary health care settings. There are also greater proportion of premature and LBW infants in urban than rural [6].

Fortunately, kangaroo mother care (KMC) is cost-effective intervention in preventing neonatal death and disability especially in low- and middle-income healthcare settings. Based on the positive outcomes of KMC, it was also acknowledged in high-resource countries [7, 8]. KMC was introduced by Edgar Rey in Colombia in 1978 [3]. The safety, feasibility, acceptability and cost-effectiveness of KMC have been proven in countries such as Ethiopia [9], Ghana [10] and Madagascar [11]. The key components of kangaroo mother care (KMC) are kangaroo position (skin-to-skin contact of the infant on the mother's chest), optimal breast feeding (exclusive and frequent breast feeding) and support to the mother and infant. Skin-to-skin position for 24 hours per day (as long as possible) is defined as continuous KMC. Skin-to-skin position for a few hours a day is defined as 
intermittent KMC. KMC have more advantages over conventional new born care for mother and infant such as effective thermal control, optimal breastfeeding, infection prevention, mother-infant bonding, early discharge, decreased death and less illness. It is also a response to the separation of mothers and infants [12-14].

To fight the mortality of small infants in Ethiopia, KMC is started at black lion hospital in 1996. Since then, KMC services have been expanded at community and health care settings [15]. The service is integrated in the 2015/16-2019/20 high-impact child survival intervention package along continuum of care with target of achieving $90 \%$ coverage by 2020 . Despite the free charge of services, still the current coverage was low [16]. There is also discrepancy among regions (5\% in Amhara, 2\% in Oromia, and 2\% in Somali and 1\% in Southern region) [6]. The capital city of Southern region is Hawassa which includes KMC health care settings (two hospitals and $\mathrm{MCH}$ specialty clinic). These health care settings have been serving for more than 15 million people in southern Ethiopia and its neighboring regions of Oromia.

\subsection{METHODOLOGY}

\subsection{Study area and Study design}

An institution based cross-sectional study design was employed in hospitals and MCH specialty clinic (Hawassa University comprehensive specialized hospital, Adare general Hospital and Loke MCH specialty clinic) in Hawassa city, southern Ethiopia. Hawassa city is the capital city of southern Ethiopia and it is about $275 \mathrm{~km}$ from Addis Ababa (capital city of the country). According to 2007census report, southern region of Ethiopia is the home of 15,321,000 populations [17]. According to 2016 national EmONC assessment, of all 411,720 institutional live births of southern region, 875 preterm live births ( $<37$ weeks), 6,282 low birth weight $(<2,500$ grams) and 583 very low birth weight $(<1,500$ grams). There is greater proportion of premature and LBW babies in urban, and hospitals and MCH specialty clinics. But, KMC coverage still remains low in study area [6]. The study was done between March and May 2018.

\subsection{Study population, Sample size determinations and Sampling techniques}

Study population for our study was all sampled mothers or care takers (grandmothers, father and other relatives) among those who gave care for small infants during the data collection period in three Hawassa health care settings. Inclusion criteria: all stable premature and LBW infants of caregivers were included in the study.

The sample size was determined using a single population proportion formula on the following assumptions: the prevalence of knowledge of care takers (11.4\%) [10], 95\% confidence interval, 5\% margin of error and $10 \%$ non-response rate. Then, final sample size was 96 subjects.

This study included two hospitals and one MCH specialty clinic. These health facilities were providing KMC services in Hawassa City during the time of data collection. The sample size of each health facilities was proportionally allocated based on client load. Consecutive sampling technique was employed and each study respondent was interviewed consecutively until required sample size reached.

\subsection{Operational definitions}

Kangaroo mother care: It includes early, prolonged and continuous skin-to-skin contact, exclusive breastfeeding and support to the mother and infant.

Care takers: refers mothers or other family members (father, grandmother or relatives) who providing the care for premature/LBW infants in the mothers' absence or when she needs rest.

Small Infants: A baby who is born preterm with low birth weight.

Preterm birth: Delivery occurring before 37 weeks of gestational age.

Low-birth-weight: Birth weight less than 2500g (up to and including $2499 \mathrm{~g}$ ).

Intermittent: $\mathrm{KMC}$ is practiced two to three times in a day and not included the night.

Continuous: $\mathrm{KMC}$ is practiced continuously in a day and included night, interrupted only for changing diapers.

Knowledgeable: Those participants responded 50\% and more knowledge questions correctly are categorized as knowledgeable.

Good practice: Those participants responded 50\% and more practice questions correctly are categorized as having good attitude.

\subsection{Data collection Instruments and procedure}

An interviewer administered structured questionnaire was developed by reviewing different literatures and translated into local language (Amharic) then back translated to English language. Before conducting the study, pre-test was conducted on 5\% in Yirgalem referral hospital which would not be involved in this study. But it is comparable set up. The questionnaire was assured for its clarity, understandability, completeness and consistence. The five BSc Midwifes were trained on how to conduct questionnaire interviews and extract information during review of records and observation to minimize information bias. Supervisor cross checked the collected data for its consistency and completeness on each day. Sociodemographics, knowledge and attitude related data were 
collected through structured interviewer administered questionnaire. The obstetric and practice related data were extracted using a checklist from the patient record and observation respectively.

\subsection{Data processing and analysis procedures}

The collected data were cleaned, coded and entered using EpiData Version 3.1 statistical software then transferred to SPSS software package version 22 for analyses. Descriptive analysis was used to determine the frequency distribution on different variables. To test the association between explanatory variables and outcome variables, Pearson chi-square was computed. Before decision, chi-square assumptions were assured. Finally, Pvalue of $<0.05$ with $95 \%$ confidence interval was confirmed as statistical significance.

\subsection{Ethical considerations}

Before conducting the study, ethical clearance was obtained from institutional review board of Hawassa University College of medical and health science and permission letter was taken from respective health facilities. Before taking informed consent, participants were informed regarding the purpose and importance of the study. Confidentiality was kept by using codes during data collection, analysis or thought process.

\subsection{RESULTS}

\subsection{Socio-demographic characteristics of participants}

A total of 86 respondents were included in the study with the response rate of $92 \%$. The mean ( $( \pm \mathrm{SD})$ age of the respondents was $29(\mathrm{SD} \pm 7)$ years and $68.6 \%$ of them were in the age group of

25-34 years. Most (73.3\%) of them were Christian and the rest 23 (26.7\%) were Muslim. Most (79\%) of respondents were from urban areas. Majority of them were Illiterate by educational status and Employed by occupational status, 63(73.3\%), and 34(39.5\%) respectively (Table 1).

\subsection{Obstetric related characteristics}

Concerning obstetric characteristics, 50(58.1\%) of them were multiparas and majority of respondents $(69.9 \%)$ had KMC counseling during ANC follow up. Majority $66(76.7 \%)$ of them delivered in KMC health care settings and most of labors $78(90.7 \%)$ were assisted by skilled birth attendant. The mean (+SD) gestational age and birth weight $32.7(\mathrm{SD} \pm 1.9)$ weeks and $1984(\mathrm{SD} \pm 504.3)$ grams respectively. Majority of them were 33-36 weeks by gestational age group and 1500-2499 grams by birth weight group, 51(59.3\%) and 57(66.3\%) respectively. Majority $75(87.2 \%)$ of deliveries were spontaneous vaginal deliveries (SVD) and $11(12.8 \%)$ by cesarean section deliveries (CS) (Table 2).

\subsection{Knowledge of care takers about the KMC}

Fifty nine $(68.6 \%)$ study subjects were knowledgeable on the benefits of kangaroo mother care (KMC) in health care settings, whereas $27(31.4 \%$ ) of them were not knowledgeable. Overall study participants have heard about kangaroo mother care (KMC). Among those, $72.7 \%$ of respondents answered it means skin to skin contact of the infant on the mother's chest, whereas the rest of them did not know. The main sources of information were: health professional $74(86 \%)$, media 56(65\%), education campaign 20(23.3\%) and posters $15(17.4 \%)$. Seventy two $(83.7 \%)$ caregivers know at least one benefit of KMC. Study subjects are asked to their knowledge on the importance of KMC: $62(72.1 \%)$ provides warmth to the baby, 58(67.4\%) promotes exclusive breast feeding, $55(64 \%)$ improves weight gain and growth, $30(34.9 \%)$ reduces hospital stay, $41(47.7 \%)$ reduce infection and 72 $(83.7 \%)$ promotes baby-mother bonding and $20(18 \%)$ less morbidity and mortality. 27 (31.4\%) of respondents listed three and below KMC benefits.

\subsection{Attitudes of care takers on KMC}

From the study subjects, 49 (57\%) of them had willingness to accept kangaroo mother care (KMC) in health care settings. 45(52.3\%) had positive feelings to learn KMC and 49(57\%) of respondents had self-confident to continue $\mathrm{KMC}$ at home after discharge. $43(50 \%)$ of them had positive opinions to give information to family members regarding practical benefits of KMC and 47 (54.7\%) of respondents would recommend $\mathrm{KMC}$ to other mothers. $36(41.9 \%)$ of participants had willingness to generate community awareness about the benefits of KMC. Majority $28(32.6 \%)$ of respondents had willingness to keep hygiene: daily bath, change of clothes and hand washing. 67 (77.9\%) of them preferred grandmothers to implement KMC.

\subsection{Practice of care takers on KMC}

Fifty three (61.6\%) study participants had a good practice regarding kangaroo mother care. Participants are asked and observed on the correct practice of Kangaroo mother care on kangaroo position, clothing during KMC, $\mathrm{KMC}$ initiation, length of KMC and breast feeding. About 47(54.7\%) of respondents performed kangaroo position in setting or semi-reclined position appropriately, whereas the rest of respondents position was 
inappropriate. Most 49(57\%) of respondents dressed the baby with cap, socks and nappy appropriately, whereas the rest of them did not dress their baby properly. Majority 59(68.6\%) of respondents implemented KMC as soon as the baby is stable and immediately following birth and 27(31.4\%) initiated KMC after 24 hours of birth. Most $55(64 \%)$ of respondents performed KMC continuously and interrupted only for changing diapers, whereas the rest of them performed intermittently. About $70(81.4 \%)$ of them feed optimal breastfeeding immediately following birth and $9(10.5 \%)$ of them feed exclusive breast feeding less frequently, whereas the rest $7(8.1 \%)$ used formula feeding. Majority $72(83.7 \%)$ mothers, 10(11.6\%) grandmothers and 4(4.7\%) husbands employed KMC.

The reasons for not practicing KMC continuously in three health settings were: lack of adequate information and skill on KMC 14(42.4\%), difficult of handling small babies 11(33.3\%), maternal health problem $9(27.3 \%)$, fear of babies becoming abusing to breast milk $3(9.1 \%)$, lack of time $2(6.1 \%)$ and pains in the breast 1(3\%) (Figure 1).

\subsection{Association of variables with knowledge and practice of KMC}

Below table show the association between knowledge of caretakers on KMC and different variables. Three variables (having delivery in KMC health care setting $(\mathrm{p}=0.018)$, being skilled delivery attendant $(\mathrm{p}=0.0001)$ and getting KMC counseling $(\mathrm{p}=0.001)$ ) had statically significant association with knowledge of caretakers regarding to KMC (Table 3). Two variables (being knowledgeable on KMC ( $\mathrm{p}=0.001)$ and being skilled birth attendant $(\mathrm{p}=0.006))$ had statically significant association with practice of caretakers (Table 4).

\subsection{Discussion}

Our study showed that the overall knowledge and practice of caretakers on kangaroo mother care were $68.6 \%$ and $61.6 \%$ respectively. This was in-line with other study [18] but it was lower than other study [10]. Reasons for these differences may be due to the cultural characteristics of the respondents, study methodology and set up of services. In this study $68.6 \%$ of the respondents started KMC immediately after birth and $31.4 \%$ started KMC after 24 hours of birth. But, our study finding was inconsistent with other studies [10, 19]. The possible reasons for these differences may be due to the lack of awareness, psychological readiness and comfortable immediately after birth. In our study $81.4 \%$ of mothers initiated breastfeeding within one hour after birth. But, this figure was greater than EDHS survey [20]. The possible reasons for these differences may be women may get adequate information access in health care settings.

In our study the participants reported the benefits of KMC such as protection from infection, warmth to the baby, exclusive breast feeding, weight gain and growth, early discharge from hospital, safety and love. These have been also reported by other studies [21-22]. However, in present study significant number of participants reported that the reasons for not practicing kangaroo mother care were: lack of knowledge and skill, maternal health problem, difficult of handling small babies, fear of babies becoming abusing to breast milk, lack of time and pains in the breast. These have been supported by other studies [23-24].

This study showed that $58 \%$ mothers have willingness to implement KMC. This finding was similar with other findings [18-19] but it was lower than other studies [11, 25]. In our study $47(54.7 \%)$ of respondents would recommend $\mathrm{KMC}$ to other mothers with low birth weight infants. It was not comparable in other studies [10, 26]. In our study, $77.9 \%$ of them preferred grandmothers and rest preferred husbands were doing KMC. This reason may be due to grand mothers are known to have a strong commitment to give care for children in Africa including Ethiopia [27].

In our study the mode of delivery, attitude, gestational age and education status had not significant association with the practice of KMC in similar to other studies [28-29]. In general, being skilled birth attendant $(p=0.0001)$, having delivery in health care settings $(p=0.018)$ and having KMC counseling $(p=0.001)$ had statically significant association with knowledge of caretakers regarding to KMC. Similarly, being knowledgeable on $\mathrm{KMC}(\mathrm{p}=0.001)$ and being skilled birth attendant $(\mathrm{p}=0.006)$ had statically significant association with practice of caretakers on kangaroo mother care at health care settings.

\subsection{Conclusion}

The finding of this study on knowledge and practice of caretakers regarding kangaroo mother care showed that $68.6 \%$ had good knowledge and $61.6 \%$ had good practice. However, there were clear gaps in knowledge and practice in some of the small infants care intervention. The main reasons for not practicing kangaroo mother care were lack of knowledge and skill, difficult handling small babies and maternal health problem.

In this study, being skilled birth attendant, having delivery in health care settings and having KMC counseling were significantly associated with caretakers' knowledge on kangaroo mother care. Moreover, being knowledgeable on kangaroo mother care and being skilled birth attendant were significantly associated with caretakers' practices on kangaroo mother care. 


\title{
6.0 Recommendations
}

Based on the findings of this study the following recommendations are made:

- Regional health offices should promote kangaroo mother care region wide through the media (television and radio).

- The mothers should get enough information about KMC during antenatal follow up and they should develop adequate skills to initiate KMC using a poster and actual case scenarios in a health care setting by health care providers.

- Furthermore, further studies should be done a more representative community based study on areas of kangaroo mother care to identify more gaps.

\subsection{Strengths \& limitations}

The strength of this study included harmonizing methods: observation of care, review of records and interview of participants for data collection. This strength may be to minimize information bias. The limitations of this study included health care settings, cross sectional study design and convenient sampling method and thus the findings may not be generalizable for community, entire population and casual cause-effect relationship may not be proven. Another limitation of this study did not investigate enabling or restraining factors such as facility infrastructure, set up of services, management and policy issues.

\author{
Abbreviation \\ ANC: Antenatal care \\ EmONC: Emergency obstetric and neonatal care \\ KMC: Kangaroo mother care \\ LBW: Low birth weight \\ MCH: Maternal and child health \\ SD: Standard deviation \\ SPSS: Statistical package for social science \\ $\mathrm{X} 2$ : Chi-square
}

\section{Declaration}

Ethics and consent

Ethical clearance was obtained from institutional review board (IRB) of Hawassa University College of medical and health science and permission letter was taken from respective health facilities.

\section{Consent for publication}

Not applicable.

Availability of data and materials

We send all which is available as there is not remaining data and materials

\section{Competent interests}

The authors declare no competing interests.

Funding and sponsor ship

The authors did not receive any specific grant for this research.

\section{Authors' contribution}

GK designed the study, participated in data collection, analysis, interpretation and drafted the manuscript. AE and HS approved the design, data collection, analysis, interpretation and critical review of the manuscript. All authors read and approved the final manuscript.

\section{Acknowledgments}

We are very thankful to Hawassa University for giving ethical clearance. We would like to acknowledge officials of respective health facilities for making accessible the needed data for this study. Finally we also want to appreciate study participants who gave their complete information and also data collectors and supervisors for their commitment to our study.

\section{Authors' information}

\section{Getinet Kassahun $^{1 *}$, Aberash Efa ${ }^{1}$, Haymanot Samuel ${ }^{2}$}

1. Department of Midwifery, College of medicine and health science, Hawassa University, Hawassa, Southern Ethiopia

2. Hawassa University comprehensive specialized hospital, Hawassa, Southern Ethiopia

\section{References}

1. WHO and UNICEF Joint Statement. (2009). Home visits for newborn child: a strategy to improve survival. 
2. Beck S, Wojdyla D, Say L, Betran AP, Merialdi M, Requejo JH, et al. (2010). The worldwide incidence of preterm birth: a systematic review of maternal mortality and morbidity. Bull World Health Organ, 88(1):3138

3. Gomez HM, Sanabria ER, Marquette CM. (1992). The Mother Kangaroo Programme. International Child Health, 3(1):55-67.

4. Ann L Jefferies and Canadian Pediatric Society, Fetus and Newborn Committee. (2012). Kangaroo care for the preterm infant and family. Paediatr Child Health, 17(3).

5. Lawn JE, Mwansa-Kambafwile J, Barros FC, Horta BL, Cousens S. (2010). Kangaroo mother care to prevent neonatal deaths due to preterm birth complications. Int J Epidemiol, 39 Supp 1:i144-154.

6. FMOH and Columbia University. ETHIOPIAN Emergency Obstetric and Newborn Care (EmONC) Assessment 2016, Ethiopia, September, 2017

7. Nyqvist KH, Anderson CG, Bergman N, Cattaneo A, Charpak N, Davanzo R, et al. (2010). State of the art and recommendations: Kangaroo mother care: application in a high-tech environment. Acta Paediatr, 99:812-819.

8. Charpak N, Ruiz-Pela JG. (2006). Resistance to implementing kangaroo mother care in developing countries, and proposed solutions. Acta Paediatr, 95:529- 534.

9. Worku B, Kassie A. (2005). Kangaroo mother care: a randomized controlled trial on effectiveness of early kangaroo mother care for the low birth weight infants in Addis Ababa, Ethiopia. J Trop Ped, 51(2):93-97.

10. Nguah SB, Wobil PN, Obeng R, Yakubu A, Kerber KJ, Lawn JE, et al. (2011). Perception and practice of kangaroo mother care after discharge from hospital in Kumasi, Ghana: a longitudinal study. BMC Pregnancy Childbirth, 11:99. http://dx.doi. org/10.1186/1471-2393-11-99

11. Shuko Nagai S, Andrianarimanana D, Rabesandratana NH, Yonemoto N, Nakayama T, Mori R. (2010). Earlier versus later continuous kangaroo mother care (KMC) for stable low-birth-weight infants: a randomized controlled trial. Acta Paediatr, 99:827-835.

12. Nyqvist KH, Anderson GC, Bergman N, Cattaneo A, Charpak N, Davanzo R, et al. (2010). Towards universal Kangaroo Mother Care: recommendations and report from the First European conference and Seventh International Workshop on Kangaroo Mother Care. Acta Paediatr, 99:820-826.

13. Conde-Agudelo A, Belizan JM, Diaz-Rossello J. (2011). Kangaroo mother care to reduce morbidity and mortality in low birth weight infants. Cochrane Database of Systematic Reviews, 3: CD002771.

14. Ludington-Hoe SM. (2011). Evidence-based review of physiologic effects of kangaroo care. Curr Women Health Rev, 7:243-53.

15. Rapid Health Facility Assessment on Service Availability and Delivery of Care to Premature and/or Low Birth Weight Babies (2016). (www.healthynewbornnetwork.org/hnn-content/uploads/KMC_Facilities_Brief_pdf.)

16. The Federal Democratic Republic of Ethiopia Ministry of Health. National Newborn and Child Survival Strategy Document Brief Summary 2015/16-2019/20. [Online]. Available: www.unicef.org/ethiopia/Child_Survival_Strategy.pdf

17. Federal Democratic Republic of Ethiopia. Population census commission and UNFPA Summary and Statistical report of the 2007. Population and Housing Census. Addis Ababa, Ethiopia, 2008. [Online]. Available: https://www.scribd.com/doc/28289334/Summary-and-Statistical-Report-of-the-2007

18. Roba AA, Binoy S, Naganuri MA. (2017). Knowledge, Attitude and Practice of Kangaroo Mother Care by Postnatal Mothers who Gave Birth to Preterm and Low Birth Weight Babies in Public Hospitals, Eastern Ethiopia. J Neonatal Biol, 6: 264. doi: 10.4172/2167-0897.1000264

19. Rasaily R, Ganguly KK, Roy M, Vani SN, Kharood N, Kulkarni R, et al. (2017). Community based cangaroo mother care for low birth weight babies: A pilot study. Indian J Med Res, 145:51-57.

20. Central Statistical Agency (CSA) [Ethiopia] and ICF. Ethiopia Demographic and Health Survey 2016. [Online]. Available:

www.dhsprogram.com/data/dataset/Ethiopia StandardDHS 2016.cfm?flag=1

21. World Health Organization. (2003). Reproductive Health. Kangaroo mother care: a practical guide. World Health Organization.

22. World Health Organization. (2012). March of Dimes, the Partnership for Maternal, Newborn \& Child Health, \& Save the Children. Born too soon: The global action report on preterm birth.

23. Seidman G, Unnikrishnan S, Kenny E, Myslinski S, Cairns-Smith S, Mulligan B, et al. (2015). Barriers and Enablers of Kangaroo Mother Care Practice: A Systematic Review. PLoS One, 10(5):e0125643.

24. Blomqvist YT, Frolund L, Rubertsson C, Nyqvist KH. (2013). Provision of Kangaroo Mother Care: supportive factors and barriers perceived by parents. Scand J Caring Sci, 27(2): 345-53.

25. Parmar VR, Kumar A, Kaur R, Parmar S, Kaur D, Basu S, et al. (2009). Experience with kangaroo mother care in a neonatal intensive care unit (NICU) in Chandigarh, India. Indian J Pediatr, 76:25-28

26. Hill Z, Tawiah-Agyemang C, Manu A, Okyere E, Kirkwood BR. (2010). Keeping newborns warm: beliefs, 
practices and potential for behavior change in rural Ghana. Trop Med Int Health, 15(10):1118-24.

27. Van Zyl M. (2010). The Ekwendeni Agogo Approach: Grandparents as agents of change for newborn survival. Save the Children.

28. Sloan NL, Camacho LW, Rojas EP, Stern C. (1994). Kangaroo mother method: randomised trial of an alternative method of care for stabilized low-birth weight infants. Maternidad Isidro Ayora Study Team. Lancet, 344(8925):782-5.

29. Lincetto O, Vos ET, Graça A, Macome C, Tallarico M, Fernandez A. (1998). Impact of season and discharge weight on complications and growth of Kangaroo Mother Care treated low birth weight infants in Mozambique. Acta Paediatr, 87(4):433-9.

Table 1: Socio-demographic characteristics of respondents in Hawassa health care settings, Southern Ethiopia, 2018.

\begin{tabular}{|l|l|}
\hline Socio demographic variable $(\mathbf{n}=\mathbf{3 3 7})$ & Number(Percentage) \\
\hline Age (in years) & $19(22.1)$ \\
$18-24$ & $59(68.6)$ \\
$25-34$ & $8(9.3)$ \\
$\geq 35$ & \\
\hline Marital status & $17(19.8)$ \\
Single & $38(44.2)$ \\
Married & $31(36)$ \\
Separate & \\
\hline Religion & $63(73.3)$ \\
Christian & $23(26.7)$ \\
Muslim & \\
\hline Educational status & $63(73.3)$ \\
Illiterate & $23(26.7)$ \\
Literate & \\
\hline Occupation & $19(22.1)$ \\
Farm produce & $33(38.4)$ \\
Business/Self employed & $34(39.5)$ \\
Employed/Salaried & \\
\hline Residence & $68(79 \%)$ \\
Urban & $20(21 \%)$ \\
Rural & \\
\hline
\end{tabular}

Table 2: Obstetrics characteristics of respondents in Hawassa health care settings, Southern Ethiopia, 2018.

\begin{tabular}{|l|l|}
\hline Number of delivery & $36(41.9)$ \\
Primi Para & $50(58.1)$ \\
Multi Para & $75(87.2)$ \\
\hline $\begin{array}{l}\text { Mode of delivery } \\
\text { Vagina delivery } \\
\text { CS section }\end{array}$ & $11(12.8)$ \\
\hline $\begin{array}{l}\text { Skilled birth attendant } \\
\text { No }\end{array}$ & $18(21)$ \\
Yes & $68(79)$ \\
\hline Delivery in KMC health care setting & $16(18.7)$ \\
No & $70(81.3)$ \\
Yes & \\
\hline Gestational age & $35(40.7)$ \\
Very preterm $(<32$ weeks $)$ & $51(59.3)$ \\
Moderate to late preterm $(<37$ weeks $)$ & \\
\hline Birth weight & $29(33.7)$ \\
Very low birth weight $(<1,500$ grams $)$ & $57(66.3)$ \\
Low birth weight $(<2,500$ grams $)$ & \\
\hline Getting KMC counseling & $27(31.4)$ \\
$\quad$ No & $59(68.6)$ \\
\hline Yes &
\end{tabular}


Table 3: Shows association of variables with caregivers' knowledge on Kangaroo mother care in Hawassa health care settings, Southern Ethiopia, 2018.

\begin{tabular}{|c|c|c|c|c|}
\hline Variables & $\begin{array}{r}\text { Status of kno } \\
\text { knowledgeable }\end{array}$ & $\frac{\text { wledge on KMC }}{\text { Not knowledgeable }}$ & Chi-square & p-value \\
\hline $\begin{array}{l}\text { Skilled birth attendant } \\
\text { No } \\
\text { Yes }\end{array}$ & $\begin{array}{l}5(27.8) \\
54(79.4)\end{array}$ & $\begin{array}{l}13(72.2) \\
14(20.6)\end{array}$ & 17.617 & 0.0001 \\
\hline $\begin{array}{l}\text { Delivery in KMC health } \\
\text { care setting } \\
\text { No } \\
\text { Yes }\end{array}$ & $\begin{array}{l}7(43.8) \\
52(74.3)\end{array}$ & $\begin{array}{l}9(56.3) \\
18(25.7)\end{array}$ & 5.638 & 0.018 \\
\hline $\begin{array}{l}\text { Marital status } \\
\text { Single } \\
\text { Married } \\
\text { Separate } \\
\end{array}$ & $\begin{array}{l}10(58.8) \\
26(68.4) \\
23(74.2) \\
\end{array}$ & $\begin{array}{l}7(41.2) \\
12(31.6) \\
8(25.8) \\
\end{array}$ & 1.205 & 0.547 \\
\hline $\begin{array}{l}\text { KMC counselling } \\
\text { No } \\
\text { Yes }\end{array}$ & $\begin{array}{l}12(44.4) \\
47(79.7)\end{array}$ & $\begin{array}{l}15(55.6) \\
12(20.3) \\
\end{array}$ & 10.666 & 0.001 \\
\hline $\begin{array}{l}\text { Religion } \\
\text { Christian } \\
\text { Muslim } \\
\end{array}$ & $\begin{array}{l}42(66.7) \\
17(73.9)\end{array}$ & $\begin{array}{l}21(33.3) \\
6(26.1)\end{array}$ & 0.441 & 0.521 \\
\hline $\begin{array}{l}\text { Education } \\
\text { Illiterate } \\
\text { Literate } \\
\end{array}$ & $\begin{array}{l}40(63.5) \\
19(82.6) \\
\end{array}$ & $\begin{array}{l}23(36.5) \\
4(17.4)\end{array}$ & 2.859 & 0.091 \\
\hline $\begin{array}{l}\text { Occupation } \\
\text { Farm produce } \\
\text { Self employed } \\
\text { Employed } \\
\end{array}$ & $\begin{array}{l}14(73.7) \\
22(66.7) \\
23(67.6) \\
\end{array}$ & $\begin{array}{l}5(26.3) \\
11(33.3) \\
11(32.4) \\
\end{array}$ & 0.300 & 0.861 \\
\hline
\end{tabular}

Table 4: Shows association of variables with caregivers' practice on Kangaroo mother care in Hawassa health care Settings, Southern Ethiopia, 2018.

\begin{tabular}{|c|c|c|c|c|}
\hline Variables & $\frac{\text { Status o }}{\text { Practice }}$ & $\frac{\text { on KMC }}{\text { practice }}$ & Chi-square $\left(\mathrm{x}^{2}\right)$ & p-value \\
\hline $\begin{array}{l}\text { Knowledge status } \\
\text { Not knowledgeable } \\
\text { Knowledgeable } \\
\end{array}$ & $\begin{array}{l}5(18.5) \\
48(81.4)\end{array}$ & $\begin{array}{l}22(81.5) \\
11(18.6)\end{array}$ & 30.929 & 0.0001 \\
\hline $\begin{array}{l}\text { Attitude status } \\
\text { Unwillingness to accept KMC } \\
\text { Willingness to accept KMC }\end{array}$ & $\begin{array}{l}15(51.7) \\
38(66.7)\end{array}$ & $\begin{array}{l}14(48.3) \\
19() 33.3\end{array}$ & 1.815 & 0.178 \\
\hline $\begin{array}{l}\text { Marital status } \\
\text { Single } \\
\text { Married } \\
\text { Separate }\end{array}$ & $\begin{array}{l}11(64.7) \\
23(60.5) \\
19(61.3)\end{array}$ & $\begin{array}{l}6(39.5) \\
15(39.5) \\
12(38.7) \\
\end{array}$ & 0.089 & 0.956 \\
\hline $\begin{array}{l}\text { KMC counselling } \\
\text { No } \\
\text { Yes }\end{array}$ & $\begin{array}{l}13(48.1) \\
40(67.8)\end{array}$ & $\begin{array}{l}14(51.9) \\
19(32.2)\end{array}$ & 3.024 & 0.082 \\
\hline $\begin{array}{l}\text { Education } \\
\text { Illiterate } \\
\text { Literate }\end{array}$ & $\begin{array}{l}16(69.6) \\
37(58.7)\end{array}$ & $\begin{array}{l}7(30.4) \\
26(41.3)\end{array}$ & 0.836 & 0.360 \\
\hline $\begin{array}{l}\text { Skilled birth attendant } \\
\text { No } \\
\text { Yes } \\
\end{array}$ & $\begin{array}{l}6(33.3) \\
47(69.1)\end{array}$ & $\begin{array}{l}12(66.7) \\
21(30.9)\end{array}$ & 7.707 & 0.006 \\
\hline $\begin{array}{l}\text { Occupation } \\
\text { Farm produce } \\
\text { Self employed } \\
\text { Employed }\end{array}$ & $\begin{array}{l}15(78.9) \\
19(57.6) \\
19(55.9)\end{array}$ & $\begin{array}{l}4(21.1) \\
14(42.4) \\
15(44.1)\end{array}$ & 3.114 & 0.221 \\
\hline
\end{tabular}




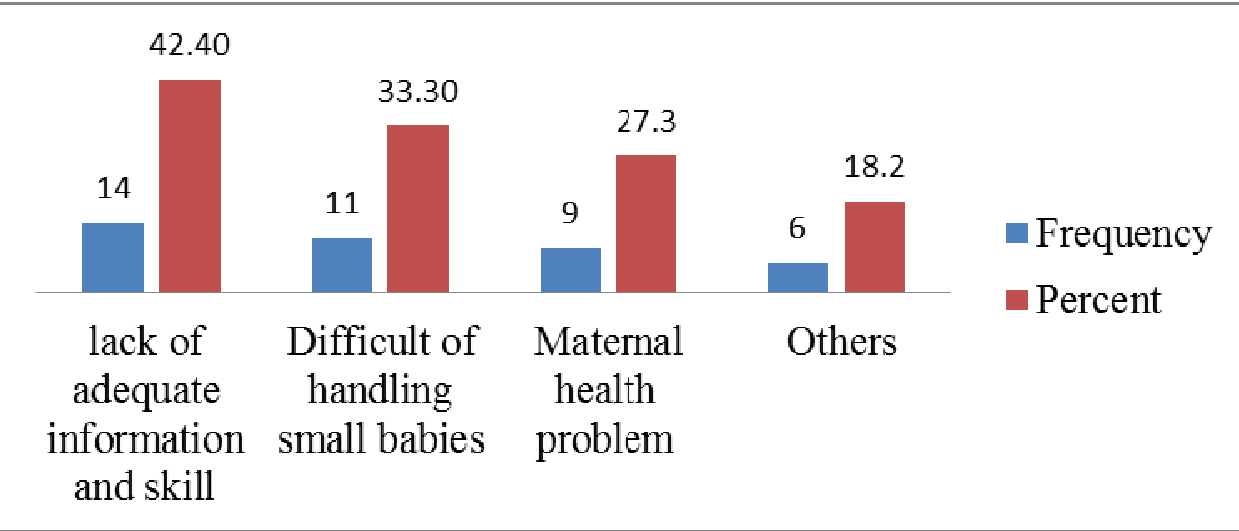

Figure 1: The reasons for not practicing Kangaroo mother care continuously in Hawassa health care Settings, Southern Ethiopia, 2018. 